\title{
Wettability and $\zeta$ Potentials of a Series of Methacrylate Polymers and Copolymers
}

\author{
A. H. HOGT, ${ }^{*}$ D. E. GREGONIS, $\dagger$ J. D. ANDRADE, $\dagger$ S. W. KIM, $\ddagger$ \\ J. DANKERT,§ AND J. FEIJEN*
}

\begin{abstract}
*Department of Chemical Technology, Section of Biomaterials, Twente University of Technology, P.O. Box 217, 7500 AE Enschede, The Netherlands; $†$ Department of Materials Science and Engineering, Department of Bioengineering and Surface Analysis Laboratory, University of Utah, Salt Lake City, Utah 84112; $\ddagger$ Department of Pharmaceutics, University of Utah, Salt Lake City, Utah 84112; and \$Department of Hospital Infections, University Hospital, Oostersingel 59, Groningen, The Netherlands
\end{abstract}

Received September 12, 1984; accepted November 27, 1984

\begin{abstract}
Polymers and copolymers of different methacrylates were synthesized and coated on glass slides. The surfaces of the polymer films were characterized by their water contact angles and $\zeta$ potentials using the Wilhelmy plate technique and streaming potential measurements, respectively. From contactangle measurements information was also obtained about mobility of surface polymer chains. Receding contact angles of methyl methacrylate (MMA) copolymers containing hydrophilic or charged units were decreased as compared to the MMA homopolymer. When charged hydroxyethyl methacrylate (HEMA) copolymers were compared with the HEMA homopolymer, the advancing contact angles increased, probably due to reorientation of surface polymer chains. The receding contact angles of poly(alkyl methacrylates) first increased and then decreased with increasing side-chain lengths. These changes were related to the mobility of the different polymers. Incorporation of positively or negatively charged groups in MMA or HEMA polymers accordingly changed the $\zeta$ potential of the polymers. (C) 1985 Academic Press, Inc.
\end{abstract}

\section{INTRODUCTION}

The tissue or blood compatibility of materials implanted or inserted in the human body is strongly dependent on the surface properties of the materials $(1,2)$. The characterization of the biomaterial surfaces is considered of ultimate importance for the development of improved biomedical devices $(3,4)$.

To study the effects of different substrate surface properties on biological interactions, a series of materials with well-characterized surface properties was prepared. Methacrylate polymers and its copolymers were chosen as model systems with varying surface hydrophobicity, surface charge, or polymer chain mobility. The synthesis and surface characterization of these polymers are described. The wettability and surface mobility of the polymers were determined by the Wilhelmy plate technique (5). The $\zeta$ potentials of a series of charged copolymer surfaces were determined by streaming potential measurements (6). Results obtained for the methyl methacrylate, hydroxyethyl methacrylate, and alkyl methacrylate (co)polymers are discussed in terms of interfacial energies and surface mobility.

\section{MATERIALS AND METHODS}

\section{Polymer Synthesis and Characterization}

The synthesis of methacrylate polymers and copolymers is well known (7-14). The methacrylate polymers and copolymers used in this study were poly(methyl methacrylate) (MMA), poly(hydroxyethyl methacrylate) (HEMA), and MMA/HEMA copolymers (mole ratios (\%): $75 / 25,50 / 50$, and $25 / 75$ ), copolymers of MMA with methacrylic acid 
(97 MMA/3 MAA and 85 MMA/15 MAA), and with trimethylaminoethyl methacrylate$\mathrm{HCl}$ salt (97 MMA/3 TMAEMA-Cl and 85 MMA/15 TMAEMA-Cl), copolymers of HEMA with MAA $(97 / 3$ and $85 / 15)$ and with TMAEMA-Cl $(97 / 3$ and $85 / 15)$, $\operatorname{poly}(n-$ butyl methacrylate) (BMA), poly(n-hexyl methacrylate) (HMA), and poly(n-dodecyl methacrylate) (DDMA). The polymers were synthesized by radical polymerization using $2,2^{\prime}$-azobis(methyl isobutyrate) as initiator as described earlier (8-10). MMA was purchased from Aldrich Chemical Company, Milwaukee, Wisconsin; HEMA was a gift from $\mathrm{Hy}$ dro-Med Sciences, Inc., New Brunswick, New Jersey; TMAEMA was purchased from Alcolac, Inc., Baltimore, Maryland; the other methacrylate esters were purchased from Polyscience, Inc., Warrington, Pennsylvania.

${ }^{1} \mathrm{H}-\mathrm{NMR}$ spectra $(270 \mathrm{MHz})$ were recorded on a Jeol FF270 NMR spectrometer. Mole ratios in the MMA/HEMA copolymers were calculated from the integrated peak areas of the HEMA-ester $\mathrm{CH}_{2}$ protons and the polymer backbone $\mathrm{CH}_{2}$ and $\mathrm{CH}_{3}$ protons. The mole ratios in the HEMA/TMAEMA-Cl copolymers were calculated from the ratio of the TMAEMA-Cl tri- $N$-methyl protons and the polymer $\mathrm{CH}_{2}$ and $\mathrm{CH}_{3}$ protons of the backbone. The samples were analyzed in 5\% (w/v) solutions in $\mathrm{CDCl}_{3}, \mathrm{DMSO}-d 6$, or $\mathrm{D}_{2} \mathrm{O}$.

The amounts of MAA and TMAEMA-Cl in the copolymers were determined by titration of methacrylic acid groups in MMA/ MAA and HEMA/MAA copolymers in a chloroform, dimethyl formamide, ethanol, and water mixture with $0.1 \mathrm{~N} \mathrm{NaOH}$ using a combined glass-calomel electrode. The amount of chloride in the trimethylaminoethyl methacrylate-HCl groups in MMA/ TMAEMA-Cl and HEMA/TMAEMA-Cl copolymers was determined by potentiometric titration with $0.01 \mathrm{~N} \mathrm{AgNO}_{3}$ in an acetic acid-water mixture using a combined silver electrode. Mole ratios of monomers in the copolymers calculated from NMR and titration data are given in Table I. Titrations were performed in duplicate.
TABLE I

Copolymer Mole Ratios Calculated from ${ }^{1}$ H-NMR and Titration Data

\begin{tabular}{lcc}
\hline & \multicolumn{2}{c}{ Mole ratio } \\
\cline { 2 - 3 } \multicolumn{1}{c}{ Copolymer } & NMR $^{e}$ & Titration \\
\hline 75 MMA/25 HEMA & $78: 22$ & - \\
50 MMA/50 HEMA & $51: 49$ & - \\
25 MMA/75 HEMA & $29: 71$ & - \\
97 MMA/3 MAA & - & $97.0: 3.0$ \\
85 MMA/15 MAA & - & $\mathbf{8 8 . 9 : 1 1 . 1}$ \\
97 MMA/3 TMAEMA-Cl & - & $96.2: 3.8$ \\
85 MMA/15 TMEAMA-Cl & - & $\mathbf{8 6 . 2 : 1 3 . 8}$ \\
97 HEMA/3 MAA & - & $97.5: 2.5$ \\
85 HEMA/15 MAA & - & $\mathbf{8 9 . 4 : 1 0 . 6}$ \\
97 HEMA/3 TMAEMA-Cl & $95: 5$ & $\mathbf{9 6 . 9 : 3 . 1}$ \\
85 HEMA/15 TMAEMA-Cl & $\mathbf{8 2 : 1 8}$ & $\mathbf{8 6 . 8 : 1 3 . 2}$ \\
\hline
\end{tabular}

${ }^{a}$ Mole ratios calculated from integrated peak areas.

\section{Preparation of Polymer Films}

Polymer films were prepared by slow, uniform dipping of chromic acid cleaned glass slides (Bev-l-edge, No. DSO, Propper Manufacturing Co., $3 \times 1$ in., $0.9-1.0 \mathrm{~mm}$ ) or microscope coverslips (Corning Type 2940, No. $\left.1 \frac{1}{2}, 24 \times 50 \mathrm{~mm}, 0.16-0.19 \mathrm{~mm}\right)$ in polymer solutions $(3-6 \%(w / v))$ which were filtered through Teflon membrane filters $(0.5$ $\mu \mathrm{m}$, Type FHLPO 4700, Millipore Corp., Bedford, Mass.).

Silane pretreatments were sometimes required to improve the adhesion of polymers to the glass. A vapor-phase silanization treatment similar to that described by Haller (15) was used. $\gamma$-Aminopropyl triethoxysilane (APS, Aldrich) and $n$-pentyl triethoxysilane (amyltriethoxysilane, nPS, Petrarch Chemicals, Inc., Bristol, Penn.) were applied. To solutions of HEMA, HEMA/MAA, and HEMA/TMAEMA-Cl copolymers, 1 mole\% hexamethylene diisocyanate (HMDIC, Aldrich) based on the amount of the moles of HEMA present was added as a crosslinker. In this way the films were effectively bound to the aminopropyl silanized glass. The films were cured for $3 \mathrm{~h}$ at $60^{\circ} \mathrm{C}$ in a nitrogen atmosphere. The polymer films used for 
streaming potential measurements were coated on the glass or silanized glass slides by spin casting using a Speedway Model EC101 spinning device (Speedway Research, Inc., Garland, Tex.) in order to obtain slides entirely covered on one side. A clean solventrinsed glass pipet was used to dispense $2 \mathrm{ml}$ of polymer solution onto the slide covering the entire surface. Typically, the slides were spun at $4000 \mathrm{rpm}$ for 15 to $20 \mathrm{~s}$. This coating procedure was repeated twice to assure film uniformity. Slides were dried as described above for the dipcoated films. The thickness of the coatings was in the range 0.1-0.7 $\mu \mathrm{m}$ as determined gravimetrically. The surface uniformity and possible surface contamination with particulates were checked with light microscopy. The data for the preparation of the thin polymer films are given in Table II.

\section{Contact-Angle Measurements}

Most polymers demonstrate both an advancing and receding water contact angle $(\theta)$.
The difference between $\theta$ advancing and $\theta$ receding is defined as contact-angle hysteresis. The contact angles were measured by using the Wilhelmy plate technique (5) as described previously (16).

The contact angles were calculated from

$$
\cos \theta=\frac{m g}{p \gamma}+\frac{V \rho g}{p \gamma},
$$

where $m$ is mass $(\mathrm{g})$ of the slide as measured with the electrobalance as a function of the immersion depth of the slide; $g$ is local gravitational force (Salt Lake City, 979.3 dyn $/ \mathrm{g}) ; p$ is perimeter of slide $(\mathrm{cm}) ; \gamma$ is surface tension of wetting liquid: for water $\gamma$ $=72.6 \mathrm{dyn} / \mathrm{cm}$ at $20^{\circ} \mathrm{C} ; V$ is volume of immersed slide at particular depth; and $\rho$ is density of wetting liquid. Straight-line approximations of the advancing and receding slopes of the measured force with the balance are made and extrapolated to zero depth of immersion of the slide, and the buoyancy factor in Eq. [1], $V \rho g / p \gamma$, can then be elim-

TABLE II

Preparation of Thin Polymer Films on Glass by Dip Coating

\begin{tabular}{|c|c|c|c|c|}
\hline Polymer & Solvent & $\begin{array}{l}\text { Conc } \\
(\%)\end{array}$ & $\begin{array}{l}\text { Adhesion } \\
\text { promotor }\end{array}$ & $\begin{array}{c}\text { Approximate film } \\
\text { thickness }(\mu \mathrm{m})\end{array}$ \\
\hline MMA & Toluene & 6 & $\mathrm{nPS}^{a}$ & 0.3 \\
\hline 75 MMA/25 HEMA & DMF & 3 & $\operatorname{APS}^{b}$ & 0.7 \\
\hline $50 \mathrm{MMA} / 50$ HEMA & $\mathrm{DMF}$ & 3 & APS & 0.3 \\
\hline 25 MMA/75 HEMA & DMF & 3 & APS & 0.2 \\
\hline HEMA & Methanol & 3 & APS & 0.3 \\
\hline 97 MMA/3 MAA & $\mathrm{CHCl}_{3}$ & 3 & APS & $\mathrm{ND}^{d}$ \\
\hline 85 MMA/15 MAA & $\mathrm{CHCl}_{3}$ & 3 & APS & 0.5 \\
\hline 97 MMA/3 TMAEMA-Cl & $\mathrm{CHCl}_{3}$ & 3 & nPS & ND \\
\hline 85 MMA/15 TMAEMA-Cl & DMF & 3 & - & 0.2 \\
\hline HEMA & $\mathrm{DMF}^{c}$ & 3 & APS & 0.3 \\
\hline 97 HEMA/3 MAA & $\mathrm{DMF}^{c}$ & 3 & APS & 0.5 \\
\hline 85 HEMA/15 MAA & $\mathrm{DMF}^{c}$ & 3 & APS & 0.2 \\
\hline 97 HEMA/3 TMAEMA-Cl & $\mathrm{DMF}^{c}$ & 3 & - & 0.2 \\
\hline 85 HEMA/15 TMAEMA-Cl & $\mathrm{DMF}^{c}$ & 3 & - & 0.1 \\
\hline BMA & Toluene & 6 & nPS & 0.4 \\
\hline HMA & Toluene & 6 & nPS & 0.3 \\
\hline DDMA & Toluene & 6 & nPS & 0.2 \\
\hline
\end{tabular}

${ }^{a}$-Pentyl silanized glass.

${ }^{b}$ Aminopropyl silanized glass.

${ }^{c}$ HMDIC (1\% with respect to moles HEMA) crosslinker added.

${ }^{d} \mathrm{ND}$, not determined. 
inated. The weight after slide retraction is used for measuring the force displacements.

Water used for the contact-angle experiments was first deionized by passing it through a mixed ion-exchange resin bed and then twice distilled in an all-glass apparatus. Sodium azide $(200 \mathrm{mg} / \mathrm{liter}$, Eastman-Kodak Co., Rochester, N. Y.) was added to this water to prevent microorganism contamination. Wettability of the charged copolymers was determined using phosphate-buffered saline (PBS, $140 \mathrm{~m} M \mathrm{NaCl}, 3 \mathrm{~m} M \mathrm{KCl}, 8.1$ $\mathrm{m} M \mathrm{Na}_{2} \mathrm{HPO}_{4}, 1.5 \mathrm{mM} \mathrm{KH}_{2} \mathrm{PO}_{4}, \mathrm{pH}$ 7.2). In PBS (pH 7.2) MAA is completely ionized $(\mathrm{p} K=4.7)$. The surface tension of water or PBS is measured to be $72.6 \pm 0.2 \mathrm{dyn} / \mathrm{cm}$ at $20^{\circ} \mathrm{C}$ using completely wetting glass microscope coverslips which were cleaned in chromic acid followed by a 3-min oxygen radiofrequency glow discharge treatment at $200 \mu \mathrm{m} \mathrm{Hg}$ at $35 \mathrm{~W}$ (Plasmod, Tegal Corp., Richmond, Calif.) (17). In Eq. [1] $\theta$ is set equal to zero, and $\gamma$, the surface tension of water, is thus calculated.

In order to investigate the effect of hydration on the surface properties of films of the charged MMA and HEMA copolymers, contact angles were measured before and after equilibration of the films in PBS for 3 and $18 \mathrm{~h}$, respectively.

\section{Streaming Potential Measurements}

To characterize the polymer films with respect to the net charge density or $\zeta$ potential, streaming potential measurements were performed in a parallel-plate system as described by Van Wagenen and Andrade (18). The plate separation was $130 \mu \mathrm{m}$. The measurement techniques and hydrodynamic requirements have been detailed by Van Wagenen et al. (6). Streaming potentials, $E$, are measured at various driving pressures, $P$, up to 8 $\mathrm{cm} \mathrm{Hg}$.

In this range a laminar Poiseuille flow is established and $\Delta E / \Delta P$ is linear. The $\zeta$ potential is calculated from

$$
\psi_{\zeta}=8.4922 \times 10^{8} \frac{\Delta E K_{\mathrm{B}} \eta}{\Delta P_{\epsilon}} m V
$$

Bulk values for the electrolyte viscosity ( $\eta$ $=0.010 \mathrm{P})$ and the dielectric constant ( $\epsilon$ $=80.14)$ at $20^{\circ} \mathrm{C}$ were obtained from literature (19). Specific conductance of bulk electrolyte, $K_{\mathrm{B}}$, was calculated on the basis of a measured ac resistance $\left(R_{\mathrm{ac}}=190 \mathrm{ohm}\right)$ in a precalibrated, platinum conductivity cell $\left(C=0.274 \mathrm{~cm}^{-1}\right)$ where $K_{\mathrm{B}}$ was $C / R_{\mathrm{ac}}$. The streaming electrolyte was $0.01 \mathrm{MKCl}, 8 \times 10^{-4}$ $M \mathrm{Na}_{2} \mathrm{HPO}_{4}, 2 \times 10^{-4} M \mathrm{KH}_{2} \mathrm{PO}_{4}, \mathrm{pH} 7.4$.

\section{$X$-Ray Photoelectron Spectroscopy}

X-Ray photoelectron spectroscopy (XPS) studies were done with a Hewlett-Packard 5950B instrument using monochromatic $\mathrm{Al} K \alpha_{1,2}$ radiation $(1487 \mathrm{eV})$ with $800 \mathrm{~W}$ power at the anode; the spectra were charge referenced to the $\mathrm{C} 1 s$ alkyl binding energy at $284 \mathrm{eV}$. Photoelectron spectra were obtained utilizing high-resolution scans over a $20-\mathrm{eV}$ binding energy range. As the HewlettPackard instrument used has a sample geometry in which the detected electrons are in a path $38.5^{\circ}$ from the surface plane, about $63 \%$ of the signal detected is from the topmost $40 \AA$ of the sample.

\section{RESULTS}

\section{Polymers and Polymer Films}

Methyl methacrylate and hydroxyethyl methacrylate homopolymers and copolymers, charged copolymers with methacrylic acid or trimethylaminoethyl methacrylate, and different poly(alkyl methacrylates) (BHA, MMA, and DDMA) were synthesized and analyzed by ${ }^{1} \mathrm{H}-\mathrm{NMR}$ spectroscopy and titration (Table I). Calculated copolymer compositions from NMR and titration data were in agreement with the monomer mole ratios used in the polymerization mixtures.

The thin polymer films coated on glass or silanized glass were homogeneous, particulate free, and stable in PBS for at least $24 \mathrm{~h}$. The approximate film thicknesses are given in Table II. 


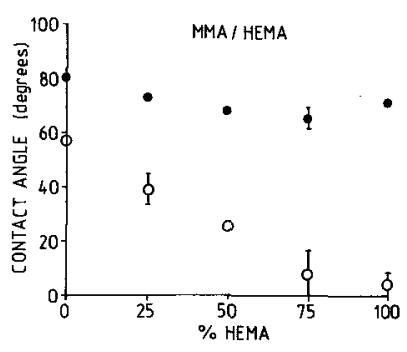

Fig. 1. Advancing ( $\bullet$ ) and receding $(O)$ contact angles of methacrylate (co)polymers as determined by Wilhelmy plate technique: Bars indicate SD of the means of at least two triplicate measurements.

\section{Contact Angles}

Dynamic advancing and receding water contact angles were determined for the polymer films using the Wilhelmy plate method. Contact angles decreased with increasing HEMA content in MMA/HEMA copolymers (Fig. 1). Receding contact angles of MMA/ MAA and MMA/TMAEMA-Cl copolymers decreased with increasing MAA or TMAEMA-Cl content, while the advancing angles were virtually unchanged (Fig. 2a). In HEMA/MAA copolymers, advancing angles slightly decreased but receding angles were practically unchanged with higher MAA content of the copolymers (Fig. 2b). The advancing contact angles of HEMA/TMAEMA$\mathrm{Cl}$ copolymers increased with higher TMAEMA-Cl content, while the receding angles did not change or only slightly increased (Fig. 2b). For the alkyl methacrylate polymer series the advancing angles increased with

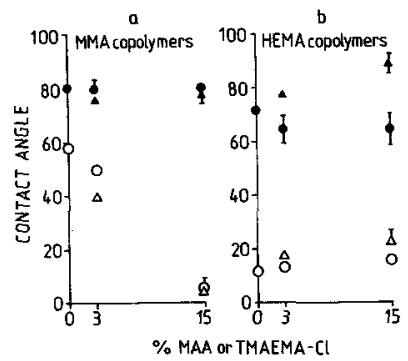

FIG. 2. Advancing $(\Theta, \Delta)$ and receding $(O, \Delta)$ contact angles of (a) copolymers of MMA with $\operatorname{MAA}(\Theta, O)$ or with TMAEMA-Cl $(\Delta, \Delta)$; and (b) copolymers of HEMA with MAA $(\bullet, O)$ or with TMAEMA-Cl $(\Delta, \Delta)$.

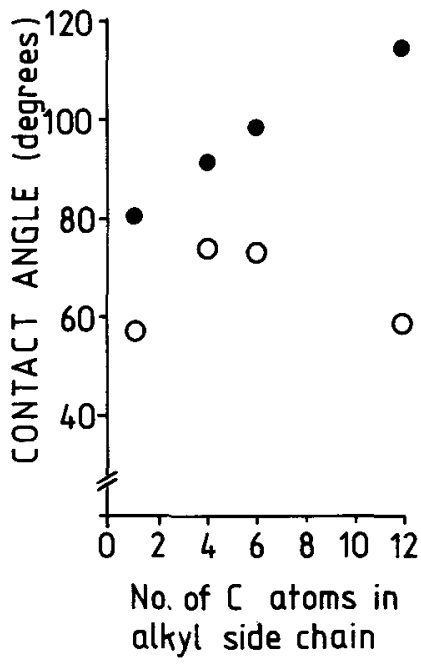

FIG. 3. Advancing (O) and receding $(O)$ contact angles of poly(alkyl methacrylates) with different alkyl sidechain lengths.

longer alkyl side-chain length (Fig. 3). The receding angles of these polymers were increased from the methyl- to butyl-substituted polymers, but decreased for those with hexyl to dodecyl side chains.

The receding angle for MMA slightly decreased after 3-h preequilibration in PBS, while the advancing angle was unchanged. The contact angles of HEMA were unchanged after equilibration of the films in PBS (Fig. 4a). The advancing angles of the MMA/

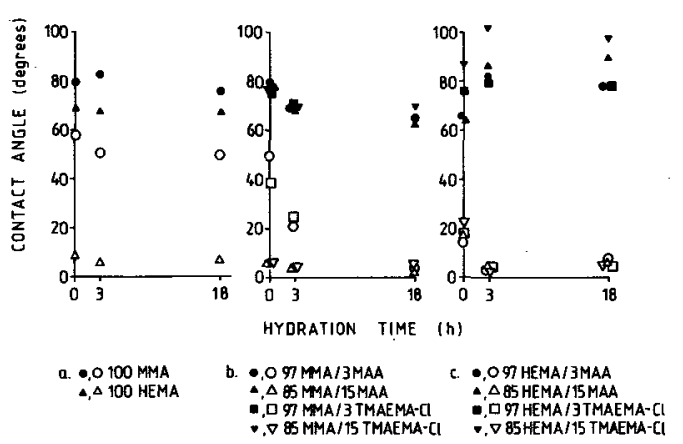

FIG. 4. Effect of preequilibration of methacrylate (co)polymer films in PBS on the advancing (closed symbols) and receding (open symbols) contact angles of (a) MMA and HEMA polymers, copolymers of (b) MMA and (c) HEMA with MAA or with TMAEMACl. 
MAA copolymers decreased after equilibration of the films in PBS (Fig. 4b). The receding angles of $97 \mathrm{MMA} / 3 \mathrm{MAA}$ strongly decreased after equilibration times up to $18 \mathrm{~h}$ in PBS. The low receding angles of the MMA copolymers with 15 MAA or TMAEMA-Cl did not decrease much further after equilibration in PBS. The contact angles of the MMA/TMAEMA-Cl copolymers showed the same pattern as that of the MMA/MAA copolymers. (The 97 MMA/3 TMAEMA-Cl copolymer film was not tested after $18 \mathrm{~h}$, because this film coated on APS was unstable.) After $3 \mathrm{~h}$ of equilibration in PBS, the advancing angles of the charged HEMA copolymers were increased, while their receding angles were decreased (Fig. 4c). The increase of the advancing angles was higher for the copolymers with $15 \%$ charged monomer units than for those with $3 \%$ charged units.

\section{Surface $\zeta$ Potential}

Streaming potential measurements were performed to determine the charge at the polymer film-water interface. The $\Delta E / \Delta P$ ratios and calculated $\zeta$ potentials of polymer films of charged MMA and HEMA copolymers preequilibrated in PBS for $3 \mathrm{~h}$ are given in Table III. Radiofrequency glow discharge cleaned "Bev-l-edge" glass slides had negative $\zeta$ potentials and were commonly used as a standard in the streaming potential measurements. The electrokinetic potential of the MMA and HEMA polymers was net negative. MMA and HEMA polymer films with incorporated MAA units showed increasingly negative $\zeta$ potentials with an increasing amount of bulk charge. The MMA/TMAEMA-Cl and HEMA/TMAEMA-Cl copolymers showed less negative $\zeta$ potentials than the base homopolymers. For the higher mole ratios of TMAEMA-Cl the $\zeta$ potentials of the copolymers became net positive.

The increased negative $\zeta$ potentials of MMA/MAA copolymers with respect to MMA after preequilibration in PBS for $3 \mathrm{~h}$ were diminished after preequilibration in PBS for $18 \mathrm{~h}$, whereas those of the HEMA/MAA copolymers remained constant after preequilibration in PBS for 3 to $18 \mathrm{~h}$ (Table IV).

TABLE III

$\Delta E / \Delta P$ Ratios and $\zeta$ Potentials for Glass and Polymer Films

\begin{tabular}{|c|c|c|c|c|}
\hline Material & $\begin{array}{c}\Delta E / \Delta P \\
(\mathrm{mV} / \mathrm{cm} \mathrm{Hg})\end{array}$ & $\psi_{5}(\mathrm{mV})$ & $n$ & Comment $^{\star}$ \\
\hline \multirow[t]{3}{*}{ Glass (Bev-l-edge) } & $-0.332 \pm 0.008^{b}$ & $-50.8 \pm 1.3$ & 3 & a, d \\
\hline & $-0.295 \pm 0.013$ & $-44.8 \pm 1.8$ & 3 & $\mathrm{a}, \mathrm{e}$ \\
\hline & $-0.324 \pm 0.014$ & $-49.3 \pm 2.1$ & 9 & $a, f$ \\
\hline MMA & $-0.189 \pm 0.013$ & $-28.9 \pm 2.2$ & 3 & $\mathrm{c}, \mathrm{g}$ \\
\hline 97 MMA/3 MAA & $-0.223 \pm 0.012$ & $-34.1 \pm 1.9$ & 2 & $\mathbf{d}, \mathbf{g}$ \\
\hline 85 MMA/15 MAA & $-0.271 \pm 0.016$ & $-41.1 \pm 2.3$ & 2 & $\mathrm{~d}, \mathrm{~g}$ \\
\hline 97 MMA/3 TMAEMA-Cl & $-0.056 \pm 0.022$ & $-8.6 \pm 3.4$ & 3 & $\mathbf{c}, \mathbf{g}$ \\
\hline 85 MMA/15 TMAEMA-Cl & $+0.027 \pm 0.002$ & $+4.2 \pm 0.3$ & 3 & $\mathrm{a}, \mathrm{g}$ \\
\hline HEMA $^{c}$ & $-0.054 \pm 0.007$ & $-8.2 \pm 1.0$ & 3 & $\mathbf{b}, \mathbf{g}$ \\
\hline 97 HEMA/3 MAA $^{c}$ & $-0.114 \pm 0.005$ & $-17.3 \pm 0.7$ & 3 & $\mathbf{b}, \mathbf{g}$ \\
\hline $85 \mathrm{HEMA} 15 \mathrm{MAA}^{c}$ & $-0.155 \pm 0.012$ & $-23.8 \pm 2.0$ & 3 & $\mathbf{b}, \mathbf{g}$ \\
\hline 97 HEMA/3 TMAEMA-Cl ${ }^{c}$ & $-0.023 \pm 0.013$ & $-3.4 \pm 2.0$ & 3 & $\mathbf{a}, \mathbf{g}$ \\
\hline 85 HEMA/15 TMAEMA-Cl ${ }^{c}$ & $+0.034 \pm 0.012$ & $+4.9 \pm 1.9$ & 3 & $a, g$ \\
\hline
\end{tabular}

a Silane linkage: (a) none, (b) APS, (c) nPS. Cleaning: (d) none, (e) chromic acid cleaned, (f) RFGD cleaned. Preequilibration: $(\mathrm{g})$ for $3 \mathrm{~h}$ in electrolyte.

${ }^{b}$ Mean $\pm \mathrm{SD}$ of $n$ measurements.

c HEMA, HEMA/MAA, and HEMA/TMAEMA-Cl copolymers with $1 \%$ HMDIC. 
TABLE IV

$\zeta$ Potentials of MMA/MAA and HEMA/MAA Copolymers after Preequilibration in PBS for 3 and $18 \mathrm{~h}$

\begin{tabular}{lcc}
\hline \multicolumn{1}{c}{ Material } & \multicolumn{2}{c}{$\psi_{3}(\mathrm{mV})$} \\
\cline { 2 - 3 } & $\begin{array}{c}\text { Preequilibration } \\
\text { for } 3 \mathrm{~h} \text { in PBS }\end{array}$ & $\begin{array}{c}\text { Preequilibration } \\
\text { for } 18 \mathrm{~h} \text { in PBS }\end{array}$ \\
\hline MMA & $-28.9 \pm 2.2^{a}$ & $-27.1 \pm 1.4$ \\
97 MMA/3 MAA & $-34.1 \pm 1.9$ & $-28.3 \pm 0.1$ \\
85 MMA/15 MAA & $-41.1 \pm 2.3$ & $-25.2 \pm 0.6$ \\
HEMA $^{b}$ & $-8.2 \pm 1.0$ & -7.8 \\
97 HEMA/3 MAA & $-17.3 \pm 0.7$ & -16.2 \\
85 HEMA/15 MAA $^{b}$ & $-23.8 \pm 2.0$ & -24.2 \\
\hline
\end{tabular}

${ }^{a}$ Mean \pm SD of at least duplicate measurements.

${ }^{b}$ Crosslinked with $1 \%$ HMDIC.

\section{$X$-Ray Photoelectron Spectroscopy}

From XPS data for the TMAEMA-Cl copolymers obtained at normal electron takeoff angles of $38.5^{\circ}$ the atomic percentage of nitrogen with respect to oxygen was measured based on the peak areas and sensitivity factors of the $\mathrm{N} 1 s$ and $\mathrm{C} 1 s$ signals (Table $\mathrm{V}$ ). The measured N/C atomic ratios of the MMA and HEMA copolymers with TMAEMA-Cl were close to or slightly lower than the calculated values. In the calculated values of theoretical N/C ratios, the amount of nitrogen from the diisocyanate crosslinker was neglected, because in the base polymer HEMA with $1 \%$ HMDIC no $N$ signal could be detected at the surface using XPS.

\section{DISCUSSION}

Contact-angle measurements give useful information about the polymer-water interface. Contact angles are determined primarily by the atoms exposed in the outer $10 \AA$ of the solid surface (20). In hydrogel interfaces, which are more diffuse than those of hydrophobic polymers, the transition region between the bulk gel and free water may be of the order of $100 \AA$ or greater. Since in this study measurements were performed on polymer coatings thicker than $0.1 \mu \mathrm{m}$, it is unlikely that the angles are influenced by the support materials.
Contact-angle hysteresis of polymer surfaces, as measured by the Wilhelmy plate technique, are caused by the mobility of surface polymeric chains and their side groups or segments when no other disturbing factors are present $(3,21)$. These factors can be surface roughness or surface heterogeneity. The advancing angle is then sensitive to the low surface energy domains and the receding angle to the high surface energy domains in heterogenous materials. Because random copolymerization can be assumed for the copolymers MMA/HEMA, MMA/TMAEMA$\mathrm{Cl}$ (22) and for the charged HEMA copolymers (11), phase separation would not be present in the methacrylate polymers used in this study. Contact-angle hysteresis phenomena observed are therefore unlikely to be due to surface heterogeneity.

The contact-angle hysteresis observed in the HEMA hydrogel system can be explained by the fact that the apolar polymer backbone and $\alpha$-methyl group dominate the surface in air, while the hydrophilic hydroxyl group containing ester side chains dominates the surface in water $(4,21)$. The minimization of the interfacial energy is the driving force for the changes in the orientation of the surface molecules in different environments (3).

MMA showed contact-angle hysteresis, although it is a rigid polymer with a glass

\section{TABLE V}

Atomic Percentage of Nitrogen with Respect to Carbon Measured by XPS

\begin{tabular}{llc}
\hline & \multicolumn{2}{c}{ N/C (\%) } \\
\cline { 2 - 3 } \multicolumn{1}{c}{ Material } & Measured & Calculated $^{a}$ \\
\hline 97 MMA/3 TMAEMA-Cl & 0.7 & 0.8 \\
85 MMA/15 TMAEMA-Cl & 2.2 & 2.5 \\
97 HEMA/3 TMAEMA-Cl & 0.6 & 0.5 \\
85 HEMA/15 TMAEMA-Cl & 1.5 & 2.1 \\
\hline
\end{tabular}

${ }^{a}$ Nitrogen originating from the HMDIC crosslinker was neglected, since the N/C ratio was very low for HEMA $1 \%$ HMDIC. N/C values were calculated from the mole ratios determined by titration (Table I). 
transition temperature above $100^{\circ} \mathrm{C}$. Sidechain $\beta$ relaxations and small amounts of plasticizing water at the polymer-water interface are considered to be the cause of this hysteresis (3). The decreasing receding contact angles and increased contact-angle hysteresis in MMA/HEMA and charged MMA copolymers with higher contents of the hydrophilic or charged moieties are therefore likely due to the increased water content and surface mobility of the polymers and the ability of the charged moieties to dominate at the surface in an aqueous environment (10).

Incorporation of charge in the polymer films considerably affects the surface properties of the films. The charged MMA copolymers absorb more water than does the MMA homopolymer and their receding angles accordingly decreased with higher mole percentages of charged units incorporated. The advancing angles were virtually unchanged. The uptake of water appeared to be slower for the MMA copolymers with 3\% charged units than for those with $15 \%$ charged units as suggested by the steady decrease of the receding contact angle of $97 \mathrm{MMA} / 3 \mathrm{MAA}$ with hydration times up to $18 \mathrm{~h}$. The incorporation of charge in the HEMA hydrogel materials either does not or only slightly affects the receding contact angles. The HEMA/TMAEMA-Cl copolymers showed increased advancing angles in contrast to the unchanged advancing angles for the MMA/ TMAEMA-Cl copolymers with increasing TMAEMA-Cl content. This difference might be explained by the surface polymer chain mobility in HEMA systems, especially when they are hydrated, which enables most charged groups to be buried into the hydrogel when the films are exposed to air, thereby reducing the interfacial energy. The hydrophobic polymer backbone is in this way preferentially exposed at the surface and causes the increased advancing contact angles.

This rotation of surface polymer chains would not be possible in MMA copolymers. The same effects as with HEMA/TMAEMACl were observed with HEMA/MAA copol- ymers, when the MAA groups were ionized after hydration in PBS. If these groups were not ionized, the increase in advancing angle with higher MAA content was not observed, because the MAA groups were not buried in the bulk due to the absence of charge, and the backbone chains were thus not preferentially exposed at the surface.

In the poly(alkyl methacrylate series), longer hydrophobic alkyl side chains caused increased advancing contact angles, as expected, paralleled by an increase of the receding angles from the methyl- to the butylsubstituted methacrylate polymers. However, for the polymers with octyl to dodecyl side chains the receding angles decreased and thus the contact-angle hysteresis substantially increased. This effect might be ascribed to the lowering of the polymer glass transition temperature by the longer alkyl side chains to below room temperature for HMA and DDMA. This would enable these polymers to decrease their interfacial energy in water by additional backbone chain reorientation besides side-chain relaxations.

The neutral MMA and HEMA polymers as well as glass had a net negative $\zeta$ potential, which is generally explained by the specific adsorption from solution of potential-determining ions such as phosphate ions, $\mathrm{OH}^{-}$, and $\mathrm{Cl}^{-}(23)$.

The difference in $\zeta$ potential between MMA and HEMA might be explained by differences in the orientation and structure of water at interfaces of different hydrophilicity, influencing specific anion adsorption and subsequent interfacial charging. Glass might, moreover, expose ionized surface silanol groups $(\mathrm{p} K \simeq 5.6$ ). Differences in measured streaming potentials between rigid surfaces and hydrogel surfaces might also occur because of differences in the position of the hydrodynamic shear region at the surface. Furthermore, surface conduction of hydrogel surfaces by means of ion migration and electroosmosis might contribute to a decreased streaming potential (24).

The incorporation of positively charged 
TMAEMA-Cl or negatively charged MAA moieties in MMA or HEMA polymers resulted in a decrease or increase in net negative $\zeta$ potential, respectively. The determined $\zeta$ potentials for the hydrogels, HEMA and HEMA/MAA, were somewhat less negative than reported by Van Wagenen et al. (6). In this study $3 \%$ polymer solutions were used for spin casting of the polymer films, probably resulting in thicker films as compared to the films cast from $1 \%$ solutions by Van Wagenen et al. Longer preequilibration of MMA/MAA copolymers in the phosphate buffered $\mathrm{KCl}$ or $\mathrm{NaCl}$ solutions from 3 to $18 \mathrm{~h}$ caused a continued uptake of water as indicated by the decrease of the contact angles. The diminished $\zeta$ potentials of the MMA/MAA copolymers after longer preequilibration time in buffer might thus be caused by the increased hydrogel character of the surface. In the HEMA/MAA hydrogel series, i.e., HEMA and the HEMA/MAA copolymers which may already be fully hydrated within $3 \mathrm{~h}$ of preequilibration in buffer, no changes were observed in the $\zeta$ potential or contact angles after a longer preequilibration time in buffer.

\section{CONCLUSIONS}

- Receding contact angles as determined by the Wilhelmy plate technique of MMA copolymers containing hydrophilic or charged units were decreased as compared to the MMA homopolymer, while their advancing contact angles were changed only slightly or not at all.

-In comparison with the HEMA homopolymer, charged HEMA copolymers showed similar receding contact angles, but showed increased advancing contact angles, probably due to reorientation of surface polymer chains.

-Advancing contact angles of poly(alkyl methacrylates) increased with increasing sidechain lengths. Their receding contact angles increased from methyl- to butyl-substituted polymers, but decreased from hexyl- to dodecyl-substituted polymers, probably due to increased mobility of these polymers. $-\zeta$ Potentials of MMA and HEMA copolymers as determined by streaming potential measurements were more negative when negatively charged groups were incorporated, and less negative or even positive when positively charged groups were incorporated. $\zeta$ Potentials of charged MMA copolymers varied with the preequilibration time of the polymers with water.

\section{ACKNOWLEDGMENTS}

This study was supported by NIH Grant HL 18519 and a grant from the Netherlands Organization for Pure Research (ZWO), The Hague. Discussions with Dr. D. L. Coleman and Dr. R. A. van Wagenen are gratefully acknowledged.

\section{REFERENCES}

1. Coleman, D. L., "In Vitro Blood Materials Interactions: A Multi-Test Approach," Ph.D. thesis. University of Utah, Salt Lake City, 1980.

2. Feijen, J., Beugeling, T., Bantjes, A., and Smit Sibinga, C.Th., in "Advances in Cardiovascular Physics" (D. N. Ghista, Ed.), Vol, 3, p. 100. Karger, Basel, 1979.

3. Andrade, J. D., Gregonis, D. E., and Smith, L. M., in "Physico-chemical Aspects of Polymer Surfaces" (K. L. Mittal, Ed.), Vol. 2, p. 911 . Plenum, New York, 1983.

4. Ratner, B. D., Ann. Biomed. Eng. 11, 313 (1983).

5. Adamson, A. W., "Physical Chemistry of Surfaces," 3rd ed. Wiley-Interscience, New York, 1976.

6. Van Wagenen, R. A., Coleman, D. L., King, R. N., Triolo, P., Brostrom, L., Smith, L. M., Gregonis, D. E., and Andrade, J. D., J. Colloid Interface Sci. 84, 155 (1981).

7. Choudhary, M. S., and Varma, I. K., Eur. Polym. J. 15, 957 (1979).

8. Gregonis, D. E., Chen, C. M., and Andrade, J. D. in: "Hydrogels for Medical and Related Applications," (J. D. Andrade, Ed.), p. 88, ACS Symposium Series No. 31. Amer. Chem. Soc., Washington, D. C., 1976.

9. Gregonis, D. E., Russell, G. A., Andrade, J. D., and De Visser, A. C., Polymer 19, 1279 (1978).

10. Gregonis, D. E., Hsu, R., Buerger, D. E., Smith, L. M., and Andrade, J. D., in "Solvent-Property Relationships in Polymers" (R. B. Seymour and G. A. Stahl, Eds.), p. 120. Pergamon, New York, 1982.

11. Hattori, S., "Preparation, Characterization and Cell 
Growth of Selected Hydrophilic Methacrylates," Ph.D. thesis. University of Utah, Salt Lake City, 1980.

12. Johnsen, A., Klesper, E., and Wirthlin, T., Macromol. Chem. 177, 2397 (1976).

13. Macret, M., and Hild, G., Polymer 23, 748 (1982).

14. Ilavski, M., Dusek, K., Vacik, J., and Kopecek, J., J. Appl. Polym. Sci. 23, 2073 (1979).

15. Haller, I., J. Amer. Chem. Soc. 78, 8050 (1978).

16. Smith, L., Doyle, C., Gregonis, D. E., and Andrade, J. D., J. Appl. Polym. Sci. 26, 1269 (1982).

17. O'kane, D. F., and Mittal, K. L., J. Vac. Sci. Technol. 11, 567 (1974).

18. Van Wagenen, R. A., and Andrade, J. D., J. Colloid Interface Sci. 76, 305 (1980).

19. Weast, R. C. (Ed.), "Handbook of Chemistry and
Physics," 58th ed., p. F-49, E-61. CRC Press, Palm Beach, Fla., 1977-1978.

20. Johnson, R. E., and Dettre, R. H., in "Surface and Colloid Science" (E. Matijevic, Ed.), Vol. 2, p. 85. Wiley-Interscience, New York, 1969.

21. Holly, F. J., and Refojo, M. F., J. Biomed. Mater. Res. 9, 315 (1975).

22. King, R. N., Andrade, J. D., Ma, S. M., Gregonis, D. E., and Brostrom, L. R., J. Colloid Interface Sci. 103, 62 (1985).

23. Eagland, D., and Allen, A. P., "Surface hydration and Zeta Potential," paper presented at the International Conference on Surface and Colloids, Puerto Rico, June 1976.

24. Voigt, A., Becker, R., and Donath, E., J. Biomed. Mater. Res. 18, 317 (1984). 